\title{
Endogenous Opiates and Behavioral Responses to Environmental Novelty
}

\author{
R. J. KATZ ${ }^{1}$ AND JeRry GElbart ${ }^{2}$ \\ Mental Health Research Institute, Department of Psychiatry, \\ University of Michigan Medical Center, Ann Arbor, Michigan 48109
}

\begin{abstract}
Endogenous opiates (endorphins) mediate a variety of motivational and behavioral states. We examined the possible contributions of endorphins to the exploratory behavior of mice. Naloxone, a blocker of opiate receptors, depressed hole board exploratory activity and entry into a novel environment. It also reduced responding for sensory stimulation. Finally, a direct correlation was demonstrated between exploratory behavior on the one hand, and enkephalininduced behavioral activation on the other.
\end{abstract}

Several recently discovered peptides (enkephalins, endorphins) have been shown to possess significant in vivo psychobiological activity. The motivational effects demonstrated for these compounds include primarily changes in pleasure and pain, (Akil, 1976; Belluzzi et al., 1976; Belluzzi and Stein, 1977; Waterfield et al., 1976) and possibly also grooming, sexual behavior, and psychomotor activity (Gispen et al., 1977; Goldstein and Hanstein, 1977; Katz et al., 1978; Myerson and Terenius, 1977).

We report here an additional set of behaviors which appear to be mediated at least in part by an endogenous opiate-exploratory behavior (i.e., behavioral responses to environmental novelty) (Nissen, 1930; Montgomery, 1952; Myers and Miller, 1954; Kish, 1955; Berlyne, 1960). Opiate drugs (morphine, methadone) are known to alter patterns of exploration in rats and mice. Ambulation is increased by low doses of these drugs (Middaugh and Zemp, 1976; Nakama et al., 1972; Norton, 1977; Oka and Hosoya, 1976) as are other exploratory behaviors, such as head turning and rearing (Norton, 1977). Activation of an opiate receptor may

${ }^{1}$ To whom all correspondence should be sent.

${ }^{2}$ The authors gratefully acknowledge support provided by Postdoctoral Training Grant MH07417 from the National Institute of Mental Health (to the first author). Experiments 1 and 3 were carried out by the second author in partial fulfillment of a course requirement for a class in drugs and behavior at the University of Michigan. We are grateful to Dr. Bernard $\mathbf{J}$. Carroll for his comments and support, and to the reviewers of this paper for their suggestions. 
therefore be involved in exploration and we accordingly have examined the effects of drugs affecting narcotic receptors upon exploration in the mouse. The four tasks used to assess opiate involvement were hole board exploration (nose poking), operant responding for sensory reinforcement, entry into a novel environment, and psychomotor stimulation.

\section{GENERAL METHODS}

\section{Subjects}

A subject pool of 99 adult male Swiss-Webster albino mice (Charles River, Portage, Mich.), each 30 to $40 \mathrm{~g}$, was maintained on ad libitum food and water. For Experiments 1, 3, and 4, subjects were maintained on day/night cycles of $12 \mathrm{hr}$ and group housed four to eight mice per cage. For Experiment 2, subjects were maintained in constant dim illumination and were housed individually.

\section{Apparatus}

The hole board apparatus (Experiment 1) was modified from the design of File and Wardill (1975) and consisted of an $8.5 \times 29.5 \times 15 \mathrm{~cm}$ clear Plexiglas box with a suspended black Plexiglas floor containing two beveled 1-cm-diameter holes. Head entry into either hole allowed viewing of a diffusely lit field. The apparatus floor was washed thoroughly between tests.

The apparatus for testing sensory reinforcement (Experiment 2) was a standard operant chamber (Scientific Prototype A-100: $19 \times 20 \times 23.5 \mathrm{~cm}$ ) with a centrally located lever with an operating requirement of $6 \mathrm{~g}$. Each bar press produced a 0.5 -sec activation of a $6-\mathrm{W} 125-\mathrm{V}$ chamber light accompanied by an audible relay click.

The apparatus for testing exploration of a novel environment (Experiment 3) consists of a box with two interconnected and highly distinctive chambers. The first chamber was white and cubical $(18 \mathrm{~cm} / \mathrm{side})$ and had a grid floor. The second was black and prismatic, with a floor design of an equilateral right triangle $(18 \times 18 \times 25.4 \mathrm{in}$. $)$ and a height of $18 \mathrm{~cm}$. The black chamber had a mesh rather than a grid floor.

Exploratory activity and behavioral activation by an enkephalin analog (Experiment 4) were measured by four field sensitive activity monitors (Stoelting, Chicago) calibrated to within $5 \%$ of each other. The testing cages $(51 \times 41 \times 22 \mathrm{~cm}$ polypropylene cages; Scientific Products series 70) were placed directly on the platforms with a fresh bedding of pine chips in each cage. Additional details of this apparatus have been published elsewhere (Katz et al., 1978).

\section{Drugs}

For Experiments 1 through 3, N-allylnoroxymorphone- $\mathrm{HCl}$ (naloxone-HCl; Narcan; Endo Laboratories, Inc., N.Y.) was injected in a 
sterile vehicle solution of $0.9 \%$ sodium chloride. All injections used a standard $0.4 \mathrm{mg} / \mathrm{ml}$ solution and injection volumes of 5,10 , and $20 \mathrm{ml} / \mathrm{kg}$ to deliver 2,4 , and $8 \mathrm{mg} / \mathrm{kg}$. All injections were administered intraperitoneally, 10 to $15 \mathrm{~min}$ prior to the start of testing. Initial testing of $50 \mathrm{mice}$ (25 experimental, 25 control) revealed that no motor impairment was induced by any drug dose as measured by a grid tilted perpendicular to the floor. Fewer than $10 \%$ of any experimental or control groups fell from the grid after it had been tilted.

For Experiment 4, D-Ala ${ }^{2}$-Leu-enkephalinamide (No. 8619, Peninsula Inc., San Carlos, Calif.) was injected, $25 \mu \mathrm{g} /$ mouse, through a permanently indwelling stainless-steel intraventricular cannula that had been previously implanted stereotaxically under sodium pentobarbital anesthesia. A vehicle solution of $10 \mu l$ of Ringer-Locke solution was infused over $30 \mathrm{sec}$. The injection procedure, although employing a relatively large volume, has previously been shown to produce stable running (Katz et al., 1978). Additional details of cannula construction and injection procedure have been published elsewhere (Katz et al., 1978).

\section{Methods of Procedure}

(1) Hole board. Subjects $(n=58)$ were injected as described with drug or vehicle. Testing involved placing subjects individually within the hole board apparatus and recording entries into either hole for two consecutive 5 -min periods. Only complete entries of the nose into a hole were recorded.

(2) Sensory reinforcement. Mice $(n=7)$ maintained undisturbed for at least 7 days in a dimly lit and quiet environment received $60 \mathrm{~min}$ of initial operant shaping to bar press for a light and relay click reinforcement. They were then administered drug or vehicle injections as described and tested for responding. Sessions of $90 \mathrm{~min}$ each were spaced at least $72 \mathrm{hr}$ apart, and each subject was tested twice at each dose level. An ABAB design was used with drug and vehicle sessions following each other. This particular housing and testing regimen has, in our hands, produced stable responding over repeated testing. Baseline stability is an important consideration when repeated measures designs are employed.

(3) Novel environment. Subjects $(n=9)$ were injected as described. Testing involved placing subjects into the white compartment of the test apparatus and recording (a) latency to enter the second compartment and (b) total crossings between compartments in 5 min.

(4) Exploratory behavior-enkephalin running. Subjects $(n=25)$ were exposed to the cages and allowed to explore until $20 \mathrm{~min}$ free from any movement, as registered upon the sensors. A standard dose of enkephalin analog was then injected as described, using a Hamilton microsyringe and manual infusion procedure. The dose of enkephalin had previously been shown to induce a high stable period of sterotyped running activity (Katz 
et al., 1978). Recording continued until $20 \mathrm{~min}$ without movement. All testing began between 9:00 and 10:00 AM. Three measures of activity (total, average, and maximal activity) were recorded and compared during exploration and drug induced stimulation within subjects, using ten-min recording intervals. Total activity represented the cumulative sum of activity prior to quiescence. Mean activity was total divided by the number of 10-min blocks, and peak was the largest 10-min block occurring during exploration and drug periods for a given subject.

Statistical analysis. $t$-Tests, analysis of variance, and bivariate correlation procedures were used for all comparisons (Bruning and Kintz, 1977).

\section{EXPERIMENT 1}

The purpose of Experiment 1 was to examine the effects of narcotic blockade on hole board exploration. This form of exploratory activity is common to rodents and is susceptible to both environmental and pharmacological manipulation (Boissier and Simon, 1962; File and Wardill, 1975; Makanjuola et al., 1975; Minck et al., 1974; Nakama et al., 1972).

\section{Results}

Naloxone produced a graded and dose related decrease in hole board exploration (Fig. 1). Inspection of initial scores indicated a high degree of correlation between 0 - to 5 -min and 6- to 10-min scores within subjects $(r$ $=0.44)$. Since this correlation is significant (Fisher $Z$ transformation $=$ $3.4 ; P<0.01)$ scores were combined to simplify analysis. ANOVA using a randomized design indicated a significant drug effect $(F(3,55)=14.8 ; P<$

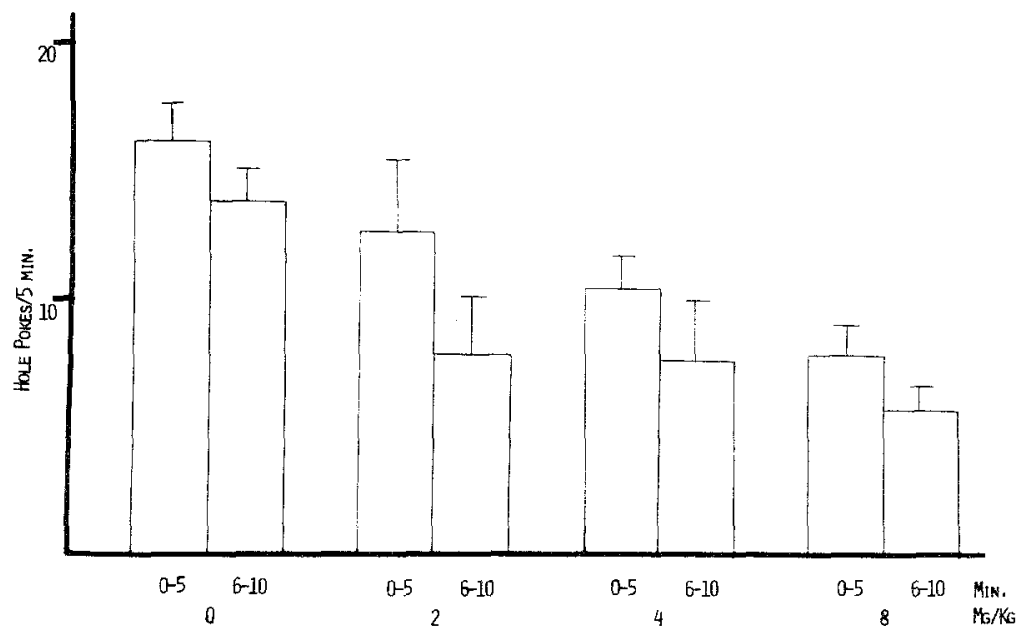

FIG. 1. Effects of naloxone-HCI upon hole poke exploratory activity in the mouse. $\mathrm{x}$ Axis includes time periods $(0-5,6-10 \mathrm{~min})$ and drug dosage $(0,2,4,8 \mathrm{mg} / \mathrm{kg}$.). All values as mean + SEM. 
0.001). Individual comparisons (Dunnetts test) indicated significant effects for 4 and $8 \mathrm{mg} / \mathrm{kg}(P<0.05$ and $P<0.01$, respectively, in comparison with $0 \mathrm{mg} / \mathrm{kg}$ ).

\section{Discussion}

The results of Experiment 1 suggest the possible involvement of an opiate receptor in hole board exploration. It might be inferred that some endogenous receptor ligand may therefore also be behaviorally involved.

Experiment 2 examined the effects of opiate receptor blockade upon an operant analog of exploration, sensory reinforcement. In the sensory reinforcement paradigm operant responding upon a manipulandum produces a discrete and response contingent alteration in the experimental chamber. In the present case, this consisted of an increase in both illumination and ambient noise.

\section{EXPERIMENT 2}

In Experiment 2, the same dosage range of naloxone as used in Experiment 1 was used to affect responding for sensory reinforcement in the apparatus previously described. Experiment 1 suggests that mice will respond less frequently to produce environmental novelty, just as they previously made fewer responses to view a novel visual environment.

Results

Responding for sensory stimulation was significantly reduced by naloxone $(F(13,57)=23.6 ; P<0.001)$. All three drug groups were significantly lower than the control group $(P<0.05$ in each case by Dunnetts test). Figure 2 indicated both a monotonic dose-response relationship and recovery between drug sessions.

\section{Discussion}

Narcotic blockade interfered with operant responding for environmental novelty as well as with hole board exploration. Both actions are consistent with opiate involvement in the motivating properties of environmental novelty. A final test of this involvement was carried out in Experiment 3.

\section{EXPERIMENT 3}

Experiment 3 examined the effects of a dose of naloxone $(8 \mathrm{mg} / \mathrm{kg})$ which had been shown to be effective in the two previous experiments and used a third exploratory situation. Subjects were placed in a box which allowed a choice of two distinctly different environments. Under conditions of high exploratory motivation, it might be predicted that more crossing between the two compartments would occur. On the other hand, 


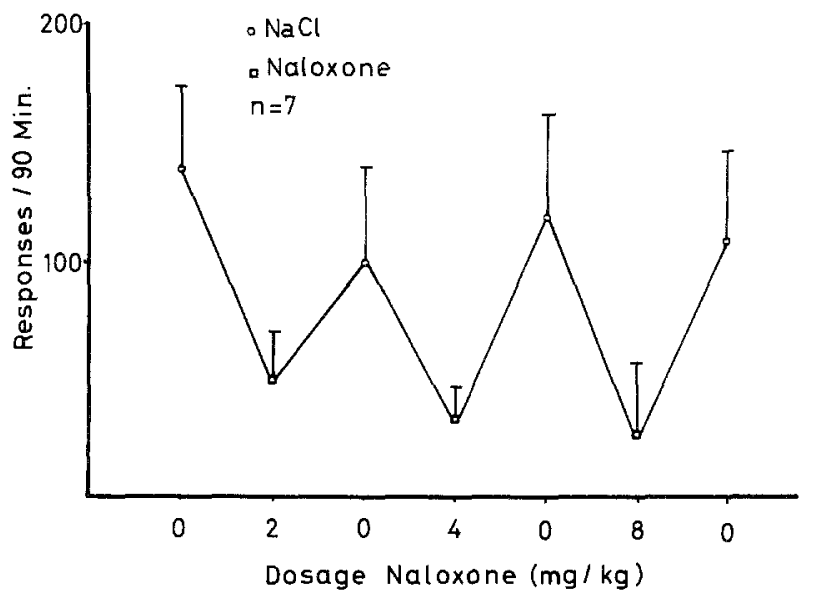

FIG. 2. Naloxone $(0,2,4,8 \mathrm{mg} / \mathrm{kg})$ reduction of operant bar pressing for sensory stimulation. All values $=$ total responses/session, mean + SEM.

animals showing lower exploratory behavior should spend less time crossing from one compartment to the other.

\section{Results}

Two measures of exploratory activity were taken (latency to enter the second compartment, total crossings between compartments). Naloxone treated subjects showed a lowering of responding on both measures, but only one (total crossing) was significant. Both findings are presented in Fig. 3. It may be seen that time to enter was slightly depressed $(t=1.3 ; P$
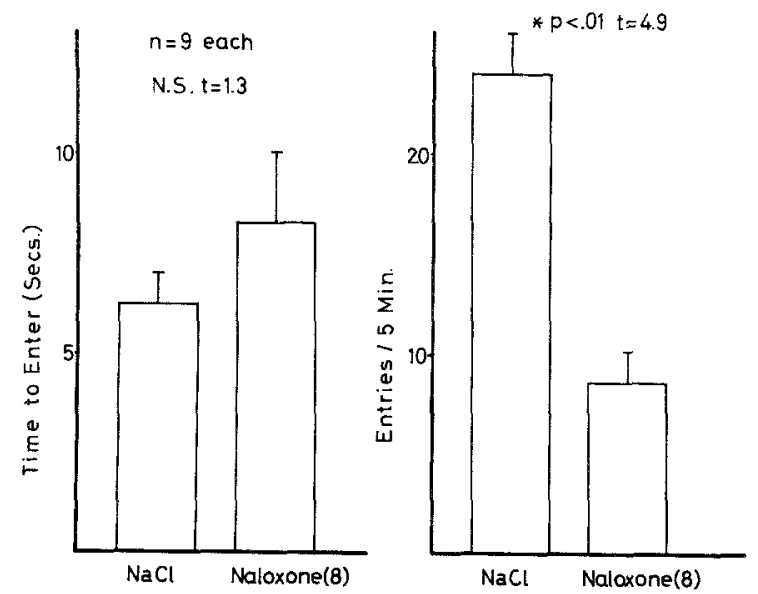

Fig. 3. Naloxone $(8 \mathrm{mg} / \mathrm{kg})$ reduction of exploration of a novel environment. y Axis $=$ time to enter (left figure) and total entries (right figure). All values as mean + SEM. 
$>0.05$ ) and that total entries (i.e., crossing between compartments) were lower under drug treatment $(t=4.9 ; P<0.01)$.

\section{Discussion}

Experiment 3, as the previous two experiments, showed a reduction in responding for novelty under conditions of narcotic blockade. Experiments 1, 2, and 3 are all consistent in their findings. Experiment 4 attempted to examine a converse interaction, whether activation by an agonist of opiate receptors would be related to exploratory activity. Opiates are known to increase exploration (see above). However, the activation caused in mice by opiates is highly atypical and cannot be classified as exploratory (Kreuger et al., 1941; Brase et al., 1977; Katz et al., 1978).

\section{EXPERIMENT 4}

Since a direct increase in motor stimulation after opiates in mice may represent behaviors extrinsic to normal exploration, we used an indirect assessment of an exploration-motor stimulation relationship. In this procedure, subjects were first allowed to explore a novel environment until they ceased moving and then were injected centrally with a standard dose of long acting opiate agonist. Any correlation between initial exploration and later opiate activation could be taken to indicate some common mechanism (presumably some common receptor for the opiate agonist).

\section{Results}

Figures 4, 5, and 6, respectively, show total, maximal, and average activity for a group of 25 mice, both during exploration and during drug activation. The three figures show a monotonic relationship between these variables across subjects, with correlations of $+0.71,+0.78$, and + 0.84 . This relationship is further confirmed by visual inspection. In all cases a significant relationship exists between variables $(t=4.81,5.9,7.5$, respectively, $d f=23$ by Fishers transformation, $P<0.0001$ ). Histology for cannula placement consisted of injecting a volume of commercially prepared black ink equivalent to the original injection volume. Ten minutes after injection subjects were decapitated under ether anesthesia and their brains were dissected and examined for the presence of ink along the ventricular surface. All subjects showed ink through the entirety of their ventricles with this procedure. The majority of subjects showed no or only limited signs of injection trauma.

\section{GENERAL DISCUSSION}

The present results using naloxone and an enkephalin analog suggest opiate involvement in exploration. Clearly the specificity of the present manipulations with respect to the established pharmacology of opiate 


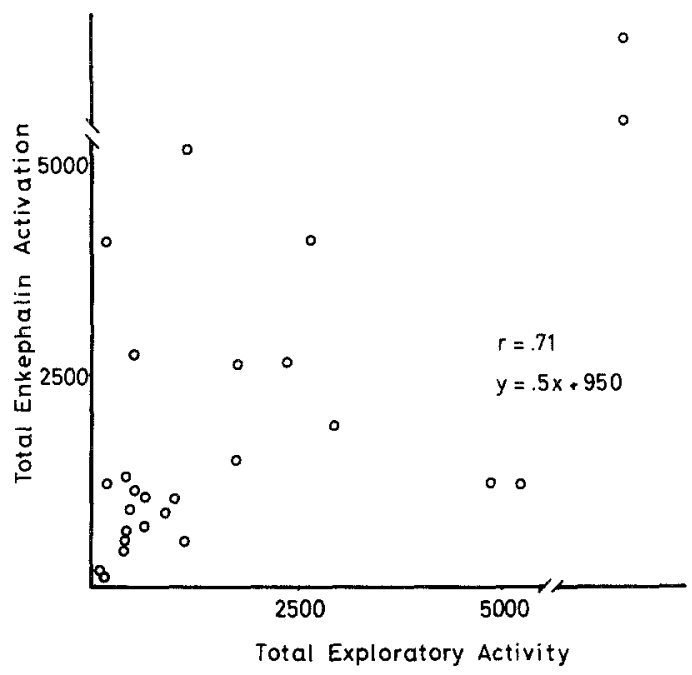

FIG. 4. Relationship of total exploratory activity ( $\mathrm{x}$ axis) and activity after activation by an enkephalin analog (y axis). Individual scores are presented.

drugs should be examined critically. For example, do the manipulations of the present study reflect established practice and normal dosage ranges? The major effects reported with naloxone occurred at $8 \mathrm{mg} / \mathrm{kg}$. In fact this dose represents a moderate to high dosage range and may involve some nonspecific effects. A careful examination of Figs. 1 and 2, however, indicates that doses as low as $2 \mathrm{mg} / \mathrm{kg}$ produce behavioral reductions of 40 to $60 \%$. Thus, effects were also seen at low and fairly specific drug doses.

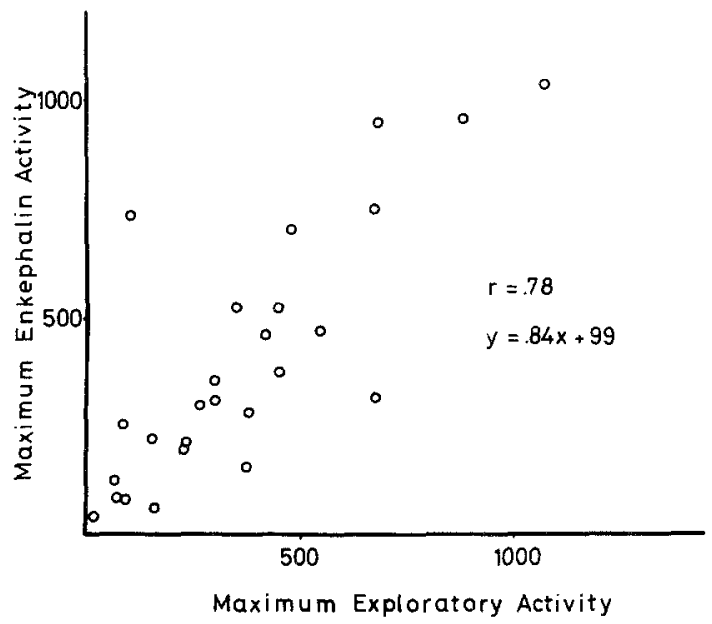

Fig. 5. Relationship of maximal activity during exploration ( $x$ axis) and maximal activity after injection of an enkephalin analog (y axis). Individual scores are presented. 


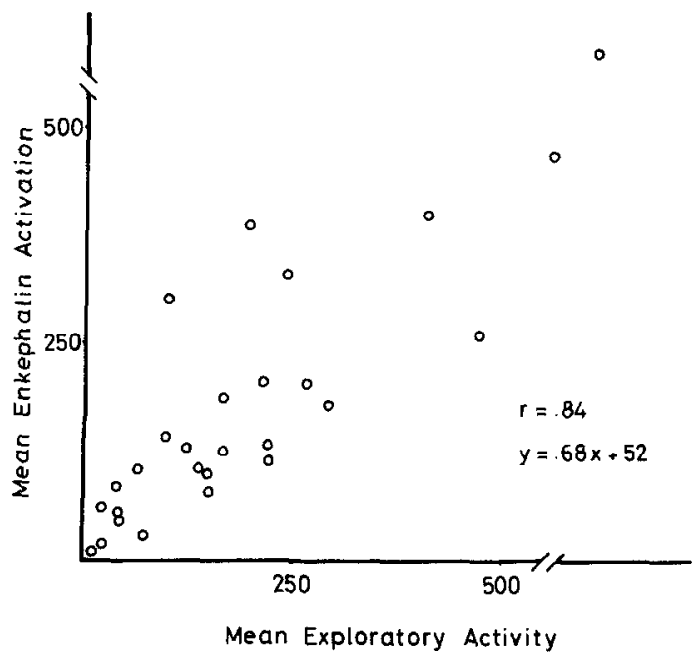

FIG. 6. Relationship of mean activity during exploration ( $\mathrm{x}$ axis) and mean activity after injection of an enkephalin analog ( $y$ axis). Individual mean scores are presented. Mean is defined as total (i.e., Fig. 4) divided by session length (number of 10 -min periods prior to 20-min quiescence).

While nonspecific effects cannot be entirely excluded it is clear that a low dose of antagonist affected two tasks with differing sensory and motor requirements. Further testing with other agonists and antagonists is currently planned, and this should additionally address the question of specificity.

It might also be argued that opiate reversal of naloxone effects would add to the specificity of our results. We have previously argued that in our experience opiates produce atypical activation and unique sensory changes at least in mice (Katz et al., 1978). This renders direct behavioral assessment of agonist-antagonist interactions difficult, although it should be noted that other reports using rats have demonstrated opiate effects predicted by the present hypothesis (see above). Also, our results with an enkephalin analog, insofar as they reflect a more general responsivity to naturally occuring ligands, at least indirectly suggest opiate agonists produce expected activating effects. It is difficult to test naturally occurring enkephalins because of their short duration of action (e.g., Belluzzi et al., 1977). However, analogs appear to produce effects similar to those of the natural compounds (e.g., Akil, 1977) and may represent reasonable substitutes, at least until some means of prolonging the action of biological compounds is possible.

The present findings suggest the involvement in exploratory activity of some endogenous compound which occupies the opiate receptor. Three possible interpretations may be advanced to explain these findings. It might be argued that some sensory alteration was produced by the drugs, 
or that some motor incapacity was produced, or finally, that some motivational change was responsible.

By the first, or sensory explanation, naloxone would presumably have to interfere with the sensory encoding of stimulus novelty, and the enkephalin analog would have to have an opposite effect. Such an explanation is unlikely, because naloxone increases rather than decreases sensory responsivity, e.g., in responding to a painful situation (Berntson and Walker, 1977; Frederickson et al., 1977) while morphine and enkephalins conversely produce a decrease rather than an increase in sensory responsivity (analgesia; Akil, 1976; Belluzzi et al., 1976). If anything, other experiments therefore argue for effects opposite to those obtained, at least on purely sensory grounds.

Objections might also be made to a purely locomotor interpretation of these findings. On the one hand, naloxone was initially tested for its ataxia producing capacity and all dosages were found to have minimal effects upon responding to a tilted grid. Naloxone also induces a hyperresponsivity to pain characterized by greater than normal movement (Frederickson et al., 1977; Belluzzi and Stein, 1977). Thus, an inability to move is probably not involved in the present results.

Both naloxone and enkephalins are known to have a variety of effects upon the motivation for reward and punishment, however (see above). It might therefore be asked if a motivational interpretation of these results is possible. Clearly, exploratory activity is mediated by motivating factors (Berlyne, 1960; Christopher and Butter, 1968) and novel stimuli do appear to have rewarding properties. One interpretation of our results might be that naloxone interferes with the rewarding properties of novel stimuli. Under such an interpretation, stimuli would be less sought after because they lose their motivating (i.e., activating and reinforcing) properties and therefore cease to reinforce exploratory behavior. Since opiates are involved with reward (Stein and Belluzzi, 1978) and since reward is one factor in exploratory behavior, this interpretation is possible.

\section{REFERENCES}

Akil, H. (1977). Opiates: Biological mechanisms. In J. D. Barchas, Y. A. Berger, R. D. Ciaranello, and G. R. Elliot (Eds.), "Psychopharmacology from Theory to Practice," pp. 292-306. New York: Oxford.

Belluzzi, J. D., Grant, N., Garsky, V., Sarantakis, D., Wise, C. D., and Stein, L. (1976). Analgesia induced in vivo by central administration of enkephalin in the rat. Nature (London) 260, 625-626.

Belluzzi, J. D., and Stein, L. (1977). Enkephalin may mediate euphoria drive reduction and reward. Nature (London) 266(7), 556-558.

Berlyne, D. E. (1960). "Conflict Arousal and Curiosity." New York: McGraw-Hill.

Berntson, G. G., and Walker, J. M. (1977). Effect of opiate receptor blockade on pain sensitivity in the rat. Brain Res. Bull. 2, 157-159.

Boissier, J. R., and Simon, P. (1962). La reaction d'exploration chez la souris (note preliminaire). Therapie 17, 1225-1232. 
Brase, D. A., Loh, H. H., and Way, E. L. (1977). Comparison of the effects of morphine on locomotor activity, analgesia and primary and protracted physical dependence in six mouse strains. J. Pharmacol. Exp. Ther. 201, 368-374.

Bruning, J. L., and Kintz, B. L. (1977). "Computational Handbook of Statistics," 2nd ed. Glenview, Ill.: Scott, Foresman.

Christopher, M., and Butter, C. M. (1968). Consummatory behaviors and locomotor exploration evoked from self stimulation sites in rats. J. Comp. Physiol. Psychol. 66, 335339.

File, S. E., and Wardill, A. G. (1975). Validity of head dipping as a measure of exploration in a modified hole board. Psychopharmacologia 44, 53-59.

Frederickson, R. C. A., Burgis, V., and Edwards, J. D. (1977). Hyperalgesia induced by naloxone follows diurnal rhythm in responsivity to painful stimulation. Science 198, $756-758$.

Gispen, W. H., Wiegart, V. M., Bradbury, A. F., Hulme, E. C., Smyth, D. G., Snell, C. R., and Deinerd, D. (1977). Induction of excessive grooming in the rat by fragments of B-lipotropin. Nature (London) 264, 794-795.

Goldstein, A., and Hansteen, R. W. (1977). Evidence against involvement of endorphins in sexual arousal and orgasm in man. Arch. Gen. Psychiatry. 34, 1179-1180.

Katz, R. J., Carroll, B. J., and Baldrighi, G. (1978). Behavioral activation by enkephalins in mice Pharmacol. Biochem. Behav. 8(4) 493-496.

Kish, G. B. (1955). Learning when the onset of illumination is used as reinforcing stimulus. J. Comp. Physiol. Psychol. 48, 261-264.

Krueger, H., Eddy, N. B., and Sumwalt, M. (1941). "The Pharmacology of the Opium Alkaloids." Washington, D. C.: USPHS.

Makanjuola, R. O. A., Hill, G., Maben, J., Dow, E. C., and Ashcroft, G. W. (1977). An automated method for studying exploratory and stereotyped behavior in rats. Psychopharmacology 52, 271-277.

Middaugh, L. D., and Zemp, J. W. (1976). Effects of methadone on activity and on brain monoamines in 2 strains of mice. Pharmacol. Biochem. Behav. 5, 367-370.

Minck, K., Danneberg, P., and Knappen, F. (1974). Effects of psychotropic drugs on exploratory behavior of mice. Psychopharmacologia 39, 245-257.

Montgomery, K. C. (1952). A test of 2 explanations of spontaneous alteration. J. Comp. Physiol. Psychol. 45, 289-293.

Myers, A. K., and Miller, N. E. (1954). Failure to find a learned drive based on hunger: Evidence for learning motivated by exploration. J. Comp. Physiol. Psychol. 47, 428436.

Myerson, B. J., and Terenius, L. (1977). B.--Endorphin and male sexual behavior. Eur. J. Pharmacol. 42, 191-192.

Nakama, M., Ochiai, T., and Kowa, Y. (1972). Effects of psychotropic drugs on emotional behavior: exploratory behavior of naive rats in a holed open field. Japan. J. Pharmacol. 22, 767-775.

Nissen, H. W. (1930). A study of exploratory behavior in the white rat by means of the obstruction method. J. Genet. Psychol. 37, 361-376.

Norton, S. (1977). The structure of behavior of rats during morphine induced hyperactivity. Commun. Psychopharmacol. 1, 333-341.

Oka, T., and Hosoya, E. (1976). Effects of humoral modulators and naloxone on morphine induced changes in the spontaneous locomotor activity of the rat. Psychopharmacol. 47, 243-248.

Stein, L., and Belluzzi, J. Brain endorphins: Possible mediators of pleasurable states. In E. Usdin, (Ed.), "Opioid Peptides." London: MacMillan, in press.

Waterfield, A. A., Hughes, J., and Kosterlitz, H. W. (1976). Cross tolerance between morphine and methionine-enkephalin. Nature (London) 260, 624. 